\title{
Inhibitory CD200-receptor signaling is rewired by type I interferon.
}

Michiel van der Vlist ${ }^{1,2, \dagger}$, M. Inês Pascoal Ramos ${ }^{1,2, \dagger}$, Lucas L. van den Hoogen ${ }^{3}$, Sanne Hiddingh $^{1}$, Laura Timmerman ${ }^{1,2}$, Titus A.P. de Hond ${ }^{1,2}$, Ellen D. Kaan ${ }^{1,2}$, Maarten van der Kroef $^{3}$, Robert Jan Lebbink ${ }^{5}$, Florence M.A. Peters ${ }^{1}$, William Khoury-Hanold ${ }^{6}$, Ruth FritschStork $^{3}$, Timothy Radstake ${ }^{3}$, Linde Meyaard ${ }^{1,2, *}$

${ }^{1}$ Center for Translational Immunology, Dept. Immunology, University Medical Center Utrecht, Utrecht University, Utrecht, The Netherlands.

${ }^{2}$ Oncode Institute, Utrecht, The Netherlands.

${ }^{3}$ Center for Translational Immunology, Dept. Rheumatology \& Clinical Immunology, University Medical Center Utrecht, Utrecht University, Utrecht, The Netherlands.

${ }^{4}$ Current affiliation: Sigmund Freud University, Vienna, Austria

${ }^{5}$ Dept of Medical Microbiology, University Medical Center Utrecht, Utrecht University, Utrecht, The Netherlands.

${ }^{6}$ Dept of Immunobiology, Yale University School of Medicine, New Haven, CT, The United States of America.

$\dagger$ these authors contributed equally.

*Correspondence to: Linde Meyaard, l.meyaard@umcutrecht.nl 


\begin{abstract}
CD200 Receptor 1 (CD200R) is an established inhibitory immune receptor that inhibits TLRinduced cytokine production through Dok2 and RasGAP. RasGAP can be cleaved under certain conditions of mild cellular stress. We found that in the presence of cleaved RasGAP, CD200R loses its capacity to inhibit rpS6 phosphorylation. Furthermore, IFN $\alpha$ prestimulation of human mononuclear cells results in increased amounts of cleaved RasGAP. Coherently, upon pretreatment with increasing concentrations of IFN $\alpha, \mathrm{CD} 200 \mathrm{R}$ gradually shifts from an inhibitor to a potentiator of TLR7/8-induced IFNG mRNA production. In peripheral blood mononuclear cells from Systemic Lupus Erythematosus (SLE) patients, a prototypic type I IFN disease, we found an increased proportion of cleaved RasGAP compared to healthy controls. In line with this, in subsets of SLE patients the inhibitory function of CD200R is lost or converted to a potentiating signal for IFNG mRNA production. Thus, our data show that type I IFN rewires CD200R signaling and suggest that this cellextrinsic regulation of signaling could contribute to perpetuation of inflammation in SLE.
\end{abstract}

\title{
Key words
}

CD200-Receptor, IFNG, Type I Interferon, RasGAP, RASA1, Dok2, SLE, Lupus, Inflammation 


\section{Introduction}

Immune inhibitory receptors function to prevent collateral damage by dampening excessive immune cell activation (Ravetch and Lanier, 2000). CD200 Receptor 1 (CD200R) is known as an inhibitory immune receptor that limits pro-inflammatory responses in myeloid cells (Wright et al., 2000). Indeed, CD200fc, a Fc-fusion protein of the best-known ligand for CD200R, has been shown to have immune-suppressive capabilities (Cox et al., 2012; Huang et al., 2018; Simelyte et al., 2008; Yin et al., 2016). Mice deficient in CD200R or in CD200 are healthy under homeostatic conditions. However, upon challenge, these mice generally show increased susceptibility to autoimmune diseases and immune pathology (Hoek et al., 2000; Rygiel et al., 2008; Simelyte et al., 2008; Snelgrove et al., 2008). We previously reported that CD200R inhibits TLR7 signaling, resulting in enhanced anti-viral responses but also enhanced immunopathology upon viral infection in mice (Karnam et al., 2012). All these observations are consistent with an immune-suppressive role for the CD200R-CD200 axis. In line with this, absence of the CD200/CD200R inhibitory axis results in enhanced anti-tumor responses (Kretz-Rommel et al., 2007; McWhirter et al., 2006; Petermann et al., 2007; Rygiel et al., 2012). Coherently, tumor CD200 expression in multiple human cancers is associated with poor prognosis (Aref et al., 2018; Chen et al., 2017; El Din Fouad et al., 2018; Li et al., 2016; Moreaux et al., 2006) and blocking the CD200/CD200R inhibitory axis has been proposed as checkpoint blockade therapy in human cancer (Mahadevan et al., 2019). However, the CD200R-CD200 axis has also been reported as a co-stimulatory axis (Borriello et al., 1997; Wang et al., 2019). Furthermore, CD200R is required to 'license’ TLR2mediated immune activation by Herpes Simplex Virus 1 in macrophages (Soberman et al., 2012), and the CD200R/CD200 axis in some cases was suggested to regulate protective antitumor responses (Erin et al., 2015; Erin et al., 2018; Liu et al., 2016). Taken together, 
although CD200R is generally considered to be an inhibitory receptor, there are data that suggest a more versatile and/or complex functionality of CD200R.

CD200R signaling is different from classical inhibitory receptors: CD200R does not signal through an immune tyrosine inhibitory motif (ITIM), but through an NPxY motif (Mihrshahi et al., 2009). CD200R inhibits mitogen activated protein kinases (MAPK) by activating Dok2 and RasGAP/p120 (Mihrshahi et al., 2009; Zhang et al., 2004). The N-terminus of RasGAP/p120 contains the SH2 and SH3 domains that are required to interact with Dok2, the C-terminus contains the GTPase activating protein (GAP) domain to suppress Ras-signaling (Yang et al., 2004). RasGAP/p120 is a target of sub-lethal caspase 3 activity and can be cleaved after amino acid position 455 (Yang et al., 2004). The resulting N-terminal fragment, or 'fragment N', has different signaling properties from the full length RasGAP and activates Akt signaling to promote cell survival (Yang et al., 2004). Currently it is unknown what the individual contributions of Dok2 and RasGAP are to CD200R signaling and if cleavage of RasGAP affects the outcome of CD200R ligation.

\section{Results}

\section{CD200R signaling bifurcates and uses separate pathways to inhibit MAPK and PI3K/Akt}

In order to study which signaling pathways are regulated by CD200R we generated U937 cells that ectopically express CD200R-GFP, or a truncated signaling dead control CD200R $\Delta$ GFP (Fig. S1A). U937 cells have active Akt, Erk and rpS6 signaling pathways in culture. We assessed the outcome of CD200R ligation on these signaling pathways. Ligation of CD200RGFP, but not CD200R $\Delta$-GFP with an agonistic antibody (clone OX108) inhibited phosphorylation of mitogen-activated protein kinase (MAPK) Erk at Thr402/Tyr204 (p-Erk) and IL-8 secretion, similar to what was previously reported (Fig. 1A and S1B) (Mihrshahi et 
al., 2009). Additionally, CD200R ligation inhibited phosphorylation of ribosomal protein S6 at Ser234/235 (p-rpS6) (Fig. 1B), which is a target of the Erk/MAPK pathway and of the Akt-mTORC1 pathways. Consistently, the inhibitory function of CD200R was not limited to MAPK. We found that CD200R also inhibited Akt at residues phosphorylated by mTORC2 (p-Akt473) and PI3K/PDK (p-Akt308) (Figs. 1C and 1D). Similar to antibody-mediated ligation, ligation of CD200R with recombinant human CD200 (rhCD200) inhibited p-Erk in U937 cells (Fig. S1C). We conclude that CD200R inhibits both the MAPK/Erk pathway and the Akt pathway and their common downstream target rpS6.

CD200R recruits and activates RasGAP through Dok2 (Mihrshahi et al., 2009). To determine the relative contribution of RasGAP and Dok2 in CD200R signaling, we generated U937CD200R-GFP lines deficient for RasGAP or Dok2 using CRISPR/Cas9 (Fig. S1D). We used two different guides that yielded two different deficient U937 cell lines per target, and used these cells as separate polyclonal lines for experiments. In line with previous reports showing that Dok2 is essential for CD200R-mediated inhibition in U937 cells (Mihrshahi et al., 2009), Dok2 $^{-/-}$U937-CD200R-GFP cells failed to inhibit both p-Akt and p-Erk, and IL-8 secretion (Figs. 1E-H). In contrast, without RasGAP, CD200R remained able to inhibit p-Akt, while CD200R still failed to inhibit IL-8 secretion and p-Erk (Figs. 1E-H). These data show that CD200R-signaling bifurcates at the level of Dok2 and RasGAP, and that in the absence of RasGAP, CD200R still inhibits Akt through a pathway that involves Dok2 (Fig. 1I).

CD200R signaling changes in the presence of cleaved RasGAP.

RasGAP is synthesized as a protein of approximately $120 \mathrm{kDa}$, but can be cleaved by caspases during cell stress which disassociates the N-terminal Dok2-binding SH2-domain from the functional C-terminal GAP-domain (Yang et al., 2004). We ectopically expressed a N- 
terminal fragment of RasGAP that lacks the functional GAP-domain (RasGAP ${ }_{1-455}$ ) in U937CD200R cells (Fig. S2A) to test the functional consequence of cleaved RasGAP on CD200R function. Overexpression of RasGAP ${ }_{1-455}$ did not affect the amount of p-Erk, p-Akt308, pAkt473 or p-rpS6 without CD200R ligation (Fig. S2B). RasGAP ${ }_{1-455}$ overexpression also did not significantly affect the ability of CD200R to inhibit p-Erk or p-Akt (Fig. 2A and S2C). However, CD200R was not able to inhibit p-S6 in presence of RasGAP ${ }_{1-455}$ overexpression (Fig. 2A), showing that cleaved RasGAP affects the outcome of CD200R signaling.

Type I IFN exposure induces RasGAP cleavage.

RasGAP can be cleaved by caspase 3 (Yang et al., 2004). In human healthy control peripheral blood mononuclear cells (PBMCs) we found that type I IFN can activate caspase 3 activity (Fig. 2B), and thus potentially affects RasGAP cleavage. Indeed, 16h exposure to type I IFN (IFN $\alpha$ ) increased the amount of cleaved RasGAP fragments in PBMC and isolated monocytes (Figs. 2C -2E). We found the previously reported RasGAP cleavage fragments (fragment $\mathrm{N}$ of $\sim 56 \mathrm{kDa}$ and fragment $\mathrm{N} 2$ of $\sim 40 \mathrm{kDa}$ (Yang et al., 2004)), but also products of other sizes suggesting the involvement of other proteases. As opposed to RasGAP, IFN $\alpha$ prestimulation of PBMC and monocytes did not noticeably affect Dok2 protein expression (Figs. 2C-2E). Thus, IFN $\alpha$ stimulation induces RasGAP cleavage which may lead to a change in CD200R function.

Type I IFN exposure converts CD200R from an inhibitory to immunostimulatory receptor.

In absence of RasGAP, CD200R selectively inhibited Akt (Fig. 1). PI3K/Akt can provide negative feedback on the production of type I cytokines (Fukao et al., 2002; Ruhland and Kima, 2009). To clarify the role of Akt and Erk in the regulation of TLR7/8 signaling, we used selective inhibitors of Akt (AKTVIII, $2 \mu \mathrm{M})$ and Erk (U0126, 2.5 $\mu \mathrm{M})$ in primary human 
monocyte derived dendritic cells (moDCs) that endogenously express functional CD200R (Figs. S2C and S2D), stimulated with the TLR7/8 ligand R848. While inhibition of Erk resulted in reduced secretion of IL-8, inhibition of Akt potentiated secretion IL-8 and IL-1 $\beta$ in the majority of the donors (Fig. 3A). This demonstrates that selective inhibition of Akt, which occurs if only Dok2 and not RasGAP/p120 is functionally recruited to CD200R, could potentiate TLR7/8 mediated responses. Therefore, we assessed the function of CD200R in freshly replated moDCs versus $16 \mathrm{~h}$ IFN $\alpha$ pre-exposed moDCs seeded on immobilized recombinant human CD200 (rhCD200). In freshly replated cells, CD200R ligation by CD200 inhibited TLR7/8 ligand R848-induced p-Akt473 and p-rpS6 (Fig. 3B, 3C and S2E). IFN $\alpha$ pre-exposure marginally affected the ability of CD200R to inhibit R848-induced p-Akt473 (Fig. 3B). However, after pre-exposure to IFNa, CD200R lost inhibitory capacity for p-rpS6 in all donors and even potentiated R848-induced p-rpS6 in some donors (Fig. 3C). Overall, we conclude that IFN $\alpha$ driven inflammation favors production of cleaved RasGAP fragments which re-wires the CD200R signaling cascade.

We next assessed the inhibitory capacity of CD200R in PBMC from healthy controls (HC). In PBMC cultures, we found that IFNG mRNA and IFN $\gamma$ protein production was induced by R848 and inhibited by CD200R ligation with immobilized antibodies (Figs. 3D and 3E). IFNG mRNA in these cultures was most likely produced by NK cells, but orchestrated by monocytes (Figs. S3A-S3C) because depletion of either NK cells or monocytes(Chan et al., 1991; Okamura et al., 1995), but not T cells, prevented production of IFNG mRNA. We tested the effect of IFN $\alpha$ on CD200R function in human PBMC by using freshly isolated cells, or cells that were pre-stimulated for $16 \mathrm{~h}$ culture in medium with increasing doses of IFN $\alpha$. Freshly isolated or pre-treated HC PBMC were seeded on immobilized agonistic CD200R antibody followed by stimulation with R848. CD200R ligation inhibited R848induced IFNG mRNA expression in freshly isolated PBMC from most healthy controls. 
However, pre-treatment of PBMC with IFN $\alpha$ abrogated or reversed the capacity of CD200R to inhibit IFNG mRNA in almost all healthy donors (Figs. 3F and S3D). With increasing dose of IFN $\alpha$, the ratio of IFNG mRNA production by CD200R stimulated cells over isotype control antibody stimulated cells, changed from $<1$ (inhibition) to 0 (no effect of CD200R) to >1 (potentiation by CD200R). Of note, after overnight culture of PBMC, the inhibitory function of CD200R was also partially lost compared to freshly isolated cells (Fig. 3F). This coincided with increased mRNA expression of type I IFN-stimulated genes IFITM1 and MX1, suggesting a type I IFN-response induced by overnight culture (Fig. S3E).

Increased RasGAP cleavage in systemic lupus erythematosus PBMC

Type I IFN is a feature of many systemic auto immune diseases and its pathogenic role is well established for systemic lupus erythematosus (SLE) (Crow and Rönnblom, 2018). Blocking the type I interferon receptor subunit 1suppresses disease activity in SLE patients (Morand et al., 2020). SLE predominantly affects women (9:1 ratio) (Bennett et al., 2003) and next to type I IFN, TLR7 is implicated in its pathogenesis (Souyris et al., 2018). Furthermore, caspase activity is upregulated in SLE PBMC (Krishnan et al., 2005). We therefore assessed the availability of Dok2 and RasGAP in PBMC of SLE patients. At the protein level, both Dok2 and RasGAP expression is slightly decreased in PBMC from SLE patients (Fig. 4A). However, similar to what we observe after IFN $\alpha$ pre-stimulation in healthy control PBMC, we found an increase in cleaved RasGAP fragments in PBMC from SLE patients (Fig. 4A). This results in a lower ratio of RasGAP/p120 over cleaved RasGAP (Fig. 4B). Together these data suggest that RasGAP/p120 cleavage is enhanced by IFN $\alpha$ in vivo, which is exemplified in SLE PBMC. 
The observed increased RasGAP cleavage could result in rewiring of the CD200R signaling in (part of) SLE patients. To test this, we used PBMC from clinically well-defined SLE patients and age- and sex-matched healthy controls (HC) in two different cohorts. Antibodymediated CD200R ligation inhibited TLR7/8-mediated IFNG mRNA expression in most HC PBMC in cohort 1 (Fig. 5A, Table S1). In contrast, in SLE PBMC with a detectable IFNG mRNA response, with the exception of one patient, CD200R was unable to inhibit IFNG expression, and even potentiated IFNG expression in response to TLR7/8 ligation in 5 out of 7 SLE patients (Fig. 5A, Table S1). In a separate replication second cohort, CD200R function was also lost or inverted in 7 out of 11 SLE patients (Fig. 5B, Table S1). We excluded that CD200R function was lost because of lower CD200R expression: instead in SLE patients CD200R expression was increased on non-classical inflammatory CD14 ${ }^{-}$CD16 ${ }^{+}$ monocytes (Fig. S4A), and on CD56 ${ }^{+}$NK cells and CD19 ${ }^{+}$B cells (Fig. S4B). Medication used for SLE patients could potentially affect TLR7/8 responses and therefore CD200R function. Indeed, patients treated with hydroxychloroquine (HCQ), prednisone (Pred) or azathioprine (Aza) had decreased IFNG mRNA production after R848 stimulation (Fig. S4C). However, none of these drugs had an influence of the function of CD200R in these patients (Fig. S4C). Coherently, HCQ pre-treatment of HC PBMC did not change the function of CD200R (Fig. S4D), confirming that the functional switch we observed for CD200R was not the result of medication. Interestingly, the reversal of CD200R function was most prominent in SLE patients with Lupus Nephritis (LN), a severe manifestation of SLE, suggesting a link between aberrant CD200R inhibition and disease severity (Fig. 5C).

\section{Discussion}


Our data show that CD200R signaling bifurcates at the level of Dok2, inhibiting the PI3K/Akt pathway through Dok2, and the Ras/Erk pathway through recruitment of both RasGAP to Dok2. Type I IFN exposure results in RasGAP cleavage which changes the outcome of CD200R signaling. Consequently, CD200R potentiates R848-induced IFNG mRNA production in PBMC from HC that are exposed to type I IFN, and in untreated PBMC of part of SLE patients. This functional switch is not binary: the functional outcome of CD200R ligation seems to progress along a sliding scale from inhibition to potentiation. Previously, immune receptors with an immune tyrosine switch motif (ITSM) were shown to relay an activating or inhibitory signal by using different adaptor molecules (Wu and Veillette, 2016). For CD200R, we now propose a different mechanism, where extracellular cues can rewire the intracellular signaling of an immune receptor by inducing cleavage of their adaptor molecules. Hence, CD200R is a versatile receptor that, depending on cellextrinsic cues, can function anywhere between an inhibitory to potentiating immune receptor.

How would the immune system benefit from this versatility of CD200R? In homeostatic conditions, ligation of CD200R results in suppression of TLR responses in healthy donors (Fig. S5A). This is in line with published work in CD200 or CD200R knock-out mice showing stronger inflammatory responses and immunopathology (Hoek et al., 2000; Karnam et al., 2012; Rygiel et al., 2009; Snelgrove et al., 2008), and that treatment with CD200-fc prior to disease onset dampens renal pathology in lupus prone mice (Yin et al., 2016). We reason that this inhibitory function is a useful threshold for TLR-mediated immune activation and keeps immune cells quiescent via CD200 expressed on, for example, endothelial cells, glomeruli of the kidney, and apoptotic cells (Li et al., 2012; Rosenblum et al., 2004; Wright et al., 2001).

However, we hypothesize that in the context of infection, immune cells would need to induce rather than inhibit type I immunity to clear intracellular pathogens (Fig. S5B). Our data show 
that in such an inflammatory milieu, CD200R can switch function to potentiate TLR-induced IFNG production, a hallmark type I immunity cytokine. This potentially enhances intracellular pathogen clearance, after which inflammation will cease. Thus, we hypothesize that the versatility of CD200R aids the immune system to quickly adapt to changing inflammatory environments. This beneficial feature of CD200R goes awry the moment there is type I IFN production in the absence of an (infectious) source of inflammation that can be cleared, as is the case for SLE (Fig. S5C). In a subset of SLE patients, CD200R indeed potentiated IFNG mRNA production.

We found that CD200R signaling impinges on Erk, Akt and their common downstream target rpS6. These targets can explain potentiation of R848-induced IFNG at several levels. Akt can provide negative feedback on TLR signaling (Fukao et al., 2002; Ruhland and Kima, 2009). Indeed, inhibition of Akt potentiated inflammatory cytokine secretion in human moDC. Our data show that CD200R selectively inhibits Akt in absence of RasGAP, which would inhibit a negative feedback loop which leads to increased IFNG production. Additionally, in presence of cleaved RasGAP and after type I IFN treatment, CD200R loses its inhibitory capacity towards rpS6, a target of mTORC1. mTORC1 is involved in inflammasome activation (Moon et al., 2015), which via IL-18 production can drive IFNG mRNA production (Chan et al., 1991; Okamura et al., 1995). Rapamycin, an inhibitor of mTORC1, reduces lupus disease activity, measured among others by SLEDAI score (Fernandez et al., 2006; Lai et al., 2018). Besides direct inhibition of IFNG production by T cells, rapamycin could overrule the CD200R-effect on rpS6 as an additive layer for the effect of rapamycin treatment of SLE patients. Overall, the type I IFN-mediated rewiring of CD200R signaling to potentiate rpS6 signaling could contribute to the chronicity of SLE. 
Interfering with the CD200-CD200R pathway is suggested to be a therapeutic opportunity in cancer and auto-immunity (Kretz-Rommel and Bowdish, 2008; Mahadevan et al., 2019; Simelyte et al., 2008). However, depending on the setting, the CD200-CD200R axis is reported to either have pro- and anti-tumor effects. Our data show that the outcome of CD200R-ligation depends on the inflammatory milieu. Thus, the outcome of therapeutic targeting of the CD200-CD200R axis will likely depend on the inflammatory status of the patient at the moment of treatment.

In conclusion, we demonstrate that the signal transduction machinery of the immuneinhibitory receptor CD200R is responsive to type I IFNs thereby allowing CD200R to progressively switch from inhibitory to stimulatory signaling depending on the environment. As a general concept, the rewiring of inhibitory receptors by inflammatory cues has implications for therapeutic approaches targeting inhibitory receptors in patients. 


\section{Acknowledgments.}

We thank all members of our lab for the fruitful discussions; Marion H. Brown (University of Oxford) and Christian Widmann (University of Lausanne) for reagents; Ruslan Medzhitov (Yale University) and Hans Clevers (Hubrecht Institute) for the conceptual discussions; and Louis Bont (UMC Utrecht) and Klaas P.J.M. van Gisbergen (Sanquin) for their critical comments on the manuscript.

\section{Funding.}

MV and LM are supported by the Netherlands Organization for Scientific Research (NWO), (ALW Grants 863.14.016, 821.02.025 and NWO Vici 918.15.608). FMAP, MIPR, SH and EDK are supported by the Dutch Arthritis Foundation (Grants 06-1-403, 12-2-101, 14-02201, 18-1-403).

\section{Author contributions.}

Conceptualization (MV, MIPR, TR, LM), Methodology (MV, MIPR, TR, LM), Formal Analysis (MV, MIPR, LH, SH), Investigation (MV, MIPR, LH, SH, MK, FMAP, LT, TAPH, EDK), Resources (RJL), Patient inclusion (LH, RF, TR), Writing original draft (MV), Writing reviewing and editing (LM, TR, WKH, MIPR), Visualization (MV, MIPR), Supervision (MV, TR, LM), Project Administration (MV, LM), Funding Acquisition (MV, LM).

\section{Declaration of Interests}

The authors declare no competing interests. 


\section{Materials and Methods.}

\section{Antibodies}

\begin{tabular}{|c|c|c|c|c|c|c|}
\hline Target & Label & Vendor & Clone & Catalog\# & useage & RRID \\
\hline CD200R1 & Unlabled & eBioscience & OX108 & $\begin{array}{l}\text { 16-9201- } \\
85\end{array}$ & $10 \mathrm{ug} / \mathrm{ml}$ & AB_10804889 \\
\hline Isotype control IgG1 & Unlabled & eBioscience & P3.6.2.8.1 & $\begin{array}{l}16-4714- \\
85\end{array}$ & $10 \mathrm{ug} / \mathrm{ml}$ & AB_470162 \\
\hline CD200R1 & Unlabled & In house & OX108 & - & 3ug/ml & n.a. \\
\hline SIRL1/isotype & Unlabled & In house & $1 \mathrm{~A} 5$ & - & $1 \mathrm{ug} / \mathrm{ml}$ & n.a. \\
\hline Akt p-Thr308 & Unlabled & CST & D25E6 & 13038 & $3600 x$ & AB_2629447 \\
\hline Akt p-Ser473 & Unlabled & CST & D9E & 4060 & $200 x$ & AB_2315049 \\
\hline Erk pThr402/Tyr204 & Unlabled & CST & $\mathrm{D} 13.14 .4 \mathrm{E}$ & 4370 & $200 x$ & AB_2315112 \\
\hline rpS6 pSer234/235 & $\mathrm{PE}$ & CST & D57.2.2E & 5316 & $200 x$ & AB_10694989 \\
\hline CD14 & APC-H7 & BD Biosciences & $\mathrm{M} \varphi \mathrm{P} 9$ & 560180 & $50 x$ & AB_1645464 \\
\hline CD14 & APC-eF780 & eBioscience & 61D3 & $\begin{array}{l}47-0149- \\
42\end{array}$ & $100 x$ & AB_1834358 \\
\hline CD16 & V500 & BD Biosciences & $3 \mathrm{G} 8$ & 561394 & $50 \mathrm{x}$ & AB_10611857 \\
\hline CD19 & PerCP & Biolegend & HIB19 & 302228 & $100 x$ & AB_893272 \\
\hline CD19 & AF700 & eBioscience & HIB19 & $\begin{array}{l}\text { 56-0199- } \\
41\end{array}$ & $50 \mathrm{x}$ & AB_2043820 \\
\hline CD200 & APC & eBioscience & OX104 & $17-9200$ & $10 \mathrm{x}$ & AB_2573297 \\
\hline CD200R & $\mathrm{PE}$ & eBioscience & OX108 & 129201 & $20 x$ & AB_1210851 \\
\hline CD3 & AF700 & Biolegend & HIT-3a & 300324 & $40 x$ & AB_493739 \\
\hline CD3 & PerCP & Biolegend & UCHT1 & 300428 & $20 \mathrm{x}$ & AB_893298 \\
\hline CD56 & FITC & Biolegend & HCD56 & 318304 & $20 \mathrm{x}$ & AB_604100 \\
\hline CD56 & AF700 & BD Biosciences & B159 & 557919 & $50 x$ & AB_396940 \\
\hline CD56 & PE-CF594 & BD Biosciences & B159 & 562289 & $25 x$ & AB_11152080 \\
\hline HLA DR & FITC & BD Biosciences & M80 & 347363 & $25 x$ & AB_400291 \\
\hline HA & APC & Miltenyi & GG8-1F3.3.1 & $\begin{array}{l}130-098- \\
404\end{array}$ & $50 x$ & AB_2751024 \\
\hline RasGAP & Unlabled & Santa Cruz & B4F8 & Sc-63 & $1000 x$ & AB_628206 \\
\hline Histon 3 & Unlabled & CST & Poly clonal & 9715 & $1000 x$ & AB_331563 \\
\hline
\end{tabular}




$\begin{array}{lllllll}\text { Dok2 } & \text { Unlabled } & \text { Santa Cruz } & \text { H192 } & \text { sc-13952 } & \text { 200x } & \text { AB_2095091 } \\ \text { Donkey-a-Rabbit } & \text { AF647 } & \text { ThermoFisher } & \text { Poly clonal } & \text { A31571 } & \text { 400x } & \text { AB_162542 } \\ \text { Donkey -a -Rabbit } & \text { AF594 } & \text { ThermoFisher } & \text { Poly clonal } & \text { A21207 } & \text { 400x } & \text { AB_141637 } \\ \text { Goat-a-Rabbit } & \text { DL649 } & \text { Jackson } & \text { Poly clonal } & \text { 111-496- } & & \text { n.a. } \\ \text { Donkey-a-Rabbit } & \text { AF488 } & \text { ThermoFisher } & \text { Poly clonal } & \text { A11055 } & \text { 400x } & \text { AB_2534102 } \\ \text { Goat-a-Rabbit } & \text { HRP } & \text { ThermoFisher } & \text { Poly clonal } & \text { 31460 } & \text { 5000x } & \text { AB_228341 } \\ \text { Goat-a-Mouse } & \text { HRP } & \text { Jackson } & \text { Poly clonal } & \text { 11-005- } & & \\ & & & & \text { 5000x } & \text { n.a. }\end{array}$

\section{Gene expression quantification}

\begin{tabular}{|c|c|c|c|}
\hline Target & source & Forward & reverse \\
\hline SYBR: IFNG & & GCAAGGCTATGTGATTACAAGGC & GTGAAATAAACACACAACCCAT \\
\hline SYBR: $B 2 M$ & (Affandi et al., 2018) & GATGAGTATGCCTGCCGTGT & TGCGGCATCTTCAAACCTCC \\
\hline SYBR: GAPDH & (Gringhuis et al., 2009) & CCATGTTCGTCATGGGTGTG & GGTGCTAAGCAGTTGGTGGTG \\
\hline SYBR: $M X 1$ & (Sugai et al., 2017) & ATCCAGCCACCATTCCAAGG & TGCGATGTCCACTTCGGAAA \\
\hline SYBR: IFITM1 & (Popson et al., 2014) & CCAGCATCCGGACACCACAG & CCСCCAGCACAGCCACCTC \\
\hline \multicolumn{4}{|l|}{ Stimuli } \\
\hline & Source & Catalog\# & Concentration used \\
\hline IL-4 & R\&D Systems & 204-IL-050 & $500 \mathrm{U} / \mathrm{mL}$ \\
\hline GM-CSF & R\&D Systems & 215-GM-500 & $800 \mathrm{U} / \mathrm{mL}$ \\
\hline IFN $\alpha 2 \mathrm{a}$ & Cell Sciences & CRI003 & $1000 \mathrm{U} / \mathrm{mL}$ \\
\hline R848 & Invivogen & tlrl-r848 & $1 \mathrm{ug} / \mathrm{mL}$ \\
\hline
\end{tabular}

\section{Recombinant DNA}

\section{Source}

Plasmid: pMX CD200R-GFP

This study

Plasmid: pMX CD200R $\Delta$-GFP

This study

Plasmid: RP-418 Cas9-puro DOK2\#1

This study, adapted from (van de Weijer et al.)

Plasmid: RP-418 Cas9-puro DOK2\#2

Plasmid: RP-418 Cas9-puro RASA1\#2

This study, adapted from (van de Weijer et al.)

Plasmid: RP-418 Cas9-puro RASA1\#2

This study, adapted from (van de Weijer et al.)

Plasmid: pCL ampho

This study, adapted from (van de Weijer et al.)

Plasmid: RasGAP-HA AA1-455.lti

Kind gift from Dr. Paul Coffer (UMC Utrecht)

Plasmid: pMDLg/pRRE

Published before (Khalil et al., 2012)

Kind gift from Didier Trono (Dull et al.) 
bioRxiv preprint doi: https://doi.org/10.1101/2020.02.06.933739; this version posted February 14 , 2020. The copyright holder for this preprint (which was not certified by peer review) is the author/funder, who has granted bioRxiv a license to display the preprint in perpetuity. It is made available under aCC-BY 4.0 International license.

Plasmid: pMD2.G

Plasmid: pRSV-Rev

\section{Experimental Models: Cell Lines}

Human: U937

Human: HEK 293T

Human: Phoenix ampho

\section{Other}

\section{Reagent or Resource}

BD Fortessa (4-laser) flow cytometer

BD Canto 2 (3-laser) flow cytometer

DB AriaIII (4-laser) flow cytometer

autoMACS pro Separator

Chemidoc XRS+
Kind gift from Didier Trono (Dull et al.)

Kind gift from Didier Trono (Dull et al.)

\section{Source}

Kind gift from Dr. J. Leusen (UMC Utrecht)

Kind gift from Dr. Z. Sebestyén (UMC Utrecht)

Source

BD Bioscience

BD Bioscience

BD Bioscience

Miltenyi Biotec

Biorad 


\section{Contact for Reagent and Resource Sharing}

Further information and requests for resources and reagents should be directed to, and will be fulfilled by, Linde Meyaard (1.meyaard@umcutrecht.nl). All data is available in the manuscript or the supplementary materials. Some materials used in this manuscript are subject to Material Transfer Agreement (MTA), or can only be distributed under MTA.

\section{Cells and cell culture}

\section{Human samples}

SLE patients and age- and sex-matched healthy controls (HCs) were recruited from our outpatient clinic or in-house healthy donor service. None of the patients had evidence of an ongoing infection. The University Medical Center Utrecht medical ethical committee approved this study and all study participants signed informed consent forms. Please see Supplemental Table 1 for more detailed information on the human subjects in this study. PBMC from HC or SLE patients were isolated by ficoll gradient. Monocytes were isolated from PBMC with human CD14 MicroBeads (Miltenyi Biotec) MACS isolation using manual separation with LD columns (Miltenyi Biotec), or automated separation with an autoMACS pro Separator (Miltenyi Biotec). HC that were tested in functional experiments without direct comparison to SLE patients were all women in the age range of 18 to 62 years.

For moDC differentiation, monocytes were isolated from Buffy coats by ficoll gradient followed by percoll gradient and additional adhesion isolation. We are not informed about the sex and age of these donors. Monocytes were differentiated with GM-CSF (800U/ml) and IL4 (500U/ml) in enriched RPMI (Gibco, 10\% bovine serum, P/S, 2mM Glutamine) in a 5\% 
$\mathrm{CO}_{2}$ humidified $37^{\circ} \mathrm{C}$ incubator as previously described (Geijtenbeek et al., 2003), and used at day 6 or 7 after the start of differentiation.

All cells were maintained at $37^{\circ} \mathrm{C}$ with $5 \% \mathrm{CO} 2$ in a humidified cell culture incubator.

\section{Cell lines}

U937 (human, male origin, not authenticated) cells were maintained in RPMI (Gibco) with $10 \%$ bovine serum and $1 \% \mathrm{P} / \mathrm{S}, 5 \% \mathrm{CO}_{2}$ humidified $37^{\circ} \mathrm{C}$ incubator. Before experiments, U937 cells were differentiated with 30ng/ml Phorbol 12-myristate 13-acetate (PMA; Sigma, P8139-1MG) in 5\% FCS RPMI for 24 hours, followed by a 24-hour rest period RPMI with 5\% FCS. Unless otherwise indicated, U937 experiments were performed in 5\% FCS containing medium.

CD200R-GFP was generated by adding GFP to the c-terminal domain of CD200R, preceded by a short flexible glycine-serine (GSGSGS) spacer. CD200R $\Delta$-GFP was truncated directly after the predicted transmembrane domain. To obtain CD200R-GFP and CD200RA-GFP, U937 cells were transduced using standard retroviral transduction protocols and we used fluorescence-activated cell sorting to obtain equal expression levels.

U937 expressing full length CD200R-GFP were transduced with an in-house generated lentiviral construct containing both the gRNA and Cas9 (van de Weijer et al.). After transduction, cells were selected with puromycin and kept as poly-clonal lines. Successful deletion of the target gene was confirmed by intra-cellular antibody-staining followed by flow cytometry. 
To overexpress RasGAP ${ }_{1-455}$ CD200R-GFP expressing cells were transduced with RasGAPHA AA1-455.lti. After transduction, successful transduction was validated by intra-cellular flow cytometry.

\section{Experimental details}

Stimulation assays: Human primary cells

For CD200R-ligation experiments, $10 \mu \mathrm{g} / \mathrm{ml}$ culture grade anti-CD200R or isotype control; or $3 \mu \mathrm{g} / \mathrm{ml} \mathrm{CD} 200$ his and CD200Rhis (both Sino Biologicals) were coated onto MaxiSORB (NUNC) plates at $4^{\circ} \mathrm{C}$ overnight in PBS.

Where indicated, PBMC or moDC were pre-incubated for 16 hours with $1000 \mathrm{U} / \mathrm{ml} \mathrm{IFN} \alpha 2 \mathrm{a}$ (Cell Sciences) or enriched RPMI (RPMI, 10\% bovine serum, P/S, 2mM Glutamine) in a 5\% $\mathrm{CO}_{2}$ humidified $37^{\circ} \mathrm{C}$ incubator and washed with medium before proceeding with the experiment. Before seeding cells, the plates were washed three times with $100 \mu 1$ PBS. $100 \mu 1$ cell-suspension of moDC were seeded at $0.5 \mathrm{E} 6$ cells $/ \mathrm{ml}$ and PBMC were seeded at $1 \mathrm{E} 6 / \mathrm{ml}$ in enriched RPMI in a 96-well plate. After 2 hours of pre-incubation on the coated wells, we stimulated cells with $1 \mu \mathrm{g} / \mathrm{ml}$ of R848 (Invivogen). mRNA was isolated 4 hours after stimulation with R848, cell free supernatant was harvested 6 hours after stimulation with R848, and for flow cytometric analysis of phosphorylated proteins cells were fixed 30 minutes after R848 stimulation (see "PhosFlow Cytometry" for details).

Stimulation assays: U937-CD200R cells

PMA differentiated U937 cells were seeded in round bottom plates and incubated for 5 minutes at room temperature with anti-CD200R (in-house, OX108), anti-SIRL-1 (in-house, 
1A5) as isotype control, CD200his or CD200Rhis (both Sino Biologicals) at $3 \mu \mathrm{g} / \mathrm{ml}$. For phosphorylation assays, cells were incubated with antibodies or recombinant proteins for 60 minutes in a $5 \% \mathrm{CO}_{2}$ humidified $37^{\circ} \mathrm{C}$ incubator before fixation (see "PhosFlow" for details). For IL-8 secretion, cells were stimulated with 200ng/ml LPS (Salmonella Typhosa, Sigma) and cultured for 24 hours in a $5 \% \mathrm{CO}_{2}$ humidified $37^{\circ} \mathrm{C}$ incubator before harvesting cell-free supernatant for ELISA.

\section{Viral plasmids}

CD200R was fused to eGFP by two-step sewing PCR. First CD200R or CD200RA, and eGFP were amplified with the following primers and appropriate sized fragments were isolated from agarose gels with the PCR clean-up Gel extraction (Macherey-Nagel). PCR fragments were mixed and a consecutive PCR was done with the CD200R-F and GFP-R primers before digestion with PmlI and NotI and ligation into pMX. We used sanger sequencing to validate the sequence in the plasmid matched the expected sequence.

\begin{tabular}{|l|l|}
\hline Description of primers used for cloning & Sequence \\
\hline CD200R forward, PmlI & CACGTG GAGAAAACAGAA ATGCTCTGC \\
\hline CD200R reverse, GS-linker, AvaI & CCCGAGCCGCTACCTAAAGTATGGAGGTCTGTGT \\
\hline CD200R $\Delta$ reverse, GS-linker, AvaI & CCCGAGCCGCTACCCAACAACCAAATGAATCCCA \\
\hline GFP forward, AvaI, GS-linker & TAGCGGCTCGGGTAGCatggtgagcaagggcgagg \\
\hline eGFP reverse, NotI & GCGGCCGCTTACTTGTACAGCTCGTCCATG \\
\hline
\end{tabular}

\section{Viral transductions}

HEK293T (human, female origin) were co-transfected with pMX-CD200R or CD200RA and pCL-Ampho to produce retroviral particles, RasGAP-lentiviral vectors together with pMDL, pVSV and pRSV. U937 were infected twice with cell-free virus supernatant in presence of 4ug/ml polybrene. After 5 days of culture, $\mathrm{GFP}^{+} \mathrm{U937}$ cells were sorted and selected for equal expression. 


\section{CRISPR/Cas9.}

The following sequences were cloned in RP-418 Cas9-puro:

gRNAs targeting DOK2:

\#1: GCAGCAGCAGACGTTTGGAA

\#2: GAGACGGGGCAGTGAAACA

gRNAs targeting RASA1:

\#1: GATAGCAGAAGAACGCCTC

\#2: GCAGAAGAACGCCTCAGGC

\section{Western blot}

For western blot analysis of RasGAP, monocytes or PBMC were lysed in Laemmli at a concentration of $1 \mathrm{E} 7$ cells/mL. Where indicated, PBMC or monocytes were pre-incubated for 16 hours with 1000U/ml IFNa 2a (Cell Sciences) before lysis. Lysates were homogenized by passing them three times though a $24 \mathrm{G}$ needle. Samples were loaded under denaturing conditions on pre-cast gels (Mini-PROTEAN TGX Gels, Any kD, Bio-Rad Laboratories), or home-made $10 \%$ acrylamide gels. Protein was transferred to PVDF membranes (ImmobilonP PVDF .45um, Merck Chemicals BV). Membranes were blocked in 5\% fat-free milk (Elk, Campina, The Netherlands) in TBS 0.05\% Tween-20 (TTBS), and incubated with antibodies in 1\% Elk TTBS. The blots were imaged using SuperSignal West Femto (Thermo Fisher Scientific) on a Bio-rad Chemidoc MP.

mRNA isolation, cDNA synthesis and qPCR analysis 
mRNA from the PBMC discovery cohort was isolated using an mRNA capture kit (Roche) and cDNA was synthesized with the Reverse transcriptase kit (Promega) according to manufacturer protocol. mRNA from all other PBMC cohorts was isolated using QIAGEN mRNA micro isolation kits, followed by iScript (Biorad) cDNA synthesis according to manufacturer protocol. qPCR was performed on a QuantStudio 12K Flex or a StepOnePlus Realtime PCR system (AB Instruments) with SYBR Select Master Mix (Life Technologies), or with TaqMan, where indicated, with 5ng cDNA input and 400nM of each primer using the fast protocol with melt curve as is suggested for SYBR Select Master Mix.

Relative expression $=2^{\wedge}(\mathrm{Ct}(B 2 M)-\mathrm{Ct}($ target $))$.

Flow cytometry.

Cells were washed in flow cytometry buffer (PBS, 1\% BSA, 0.01\% sodium azide, from here on FACS buffer), and incubated with antibodies for 30 minutes on ice, washed twice and analyzed on a BD Fortessa or BD Canto II using DIVA 8 software. For multi-color experiments, compensation settings were generated using the compensation tool in DIVA 8. For data analysis we used FlowJo V10 to gate for live cells, single cells and subsequent gating as indicated in supporting figures.

Intra cellular flow cytometry for phosphorylated proteins (PhosFlow)

For analyses of phosphorylated proteins with flow cytometry, cells were fixed after stimulations with a final concentration of 3\% PFA in medium for 10 minutes at room temperature. Attached cells were detached by scraping with a plunger. Cells were harvested, transferred into a 96-well V-bottom plate and washed, and subsequently permeabilized with $100 \%$ ice old methanol for at least 5 minutes and a maximum of 2 weeks at $-20^{\circ} \mathrm{C}$. 
Before continuing with the staining protocol, the PFA/Methanol fixed cells were washed twice. Staining was performed in flow cytometry buffer and non-specific binding was prevented by incubating the cells with 5\% normal goat or mouse serum for 45 minutes at room temperature. The primary antibodies were incubated shaking for 1 hour at room temperature or 16 hours at $4^{\circ} \mathrm{C}$. Cells were washed three times in $150 \mu 1$ FACS buffer and incubated with a conjugated secondary antibody for 1 hour at room temperature while shaking. After washing three times, fluorescence was assessed on a BD Fortessa or BD Canto II using a high throughput sampler attached to the flow cytometers.

'live’ single cells were gated and median fluorescent intensity was used for quantification. For U937-CD200R and -CD200R $\Delta$ cells, cells were gated for similar expression of CD200R-GFP before assessing phosphorylation staining.

\section{ELISA}

ELISA kits used were all from Life Technologies: IL-8 (88-8086-88); IL-10 (88-7106-88); TNF (88-7346-88); IL-1 $\beta$ (88-7261-88) and IFN $\gamma$ (88-7316-88). Cell-free supernatant was harvested and stored at $-20^{\circ} \mathrm{C}$ until assayed by ELISA according to the manufacturer's protocol. MAXIsorb plates (NUNC) were coated with $50 \mu \mathrm{L}$ capture antibody diluted in coating buffer for $16 \mathrm{~h}$ at $4 \mathrm{C}$. The plates were washed once $200 \mu \mathrm{L}$ with PBC $0.05 \%$ Tween20, and blocked with $100 \mu \mathrm{L}$ blocking buffer provided with the kit. The standard was diluted as the manufacturer recommended, and both the standard curve samples and assay samples were incubated for $2 \mathrm{~h}$ at room temperature or $16 \mathrm{~h}$ at $4^{\circ} \mathrm{C}$ while shaking. Plates were washed 3 times with $200 \mu \mathrm{L}$ PBS $0.05 \%$ Tween-20, and incubated 1 hour at room temperature with $50 \mu \mathrm{L}$ detection antibody in blocking buffer, followed by 3 times $200 \mu \mathrm{L}$ washes and incubation with strep-HRP in blocking buffer. Before development with TMB substrate, the plates were washed 5 times with $200 \mu \mathrm{L}$ PBS $0.05 \%$ Tween-20. Optical densities (OD) were 
measured at 450nM and 560nM as control. With PRISM 7.1 we extrapolated from a 4parameter dose response curve based on the concentrations of the standard curve and their OD-values.

\section{Calculations}

We calculated the percentage inhibition as follows: (1-(target ${ }^{\text {anti-CD200R }} /$ target $\left.\left.^{\text {isotype }}\right)\right)^{*} 100$. and categorized the effect of CD200R as follows: neutral: less than 15\% inhibition or potentiation; inhibition: $\geq 15 \%$ inhibition; potentiation: $\geq 15 \%$ potentiation. We tested the effect of other thresholding ranging from $5 \%$ to $50 \%$ inhibition and potentiation, which did not affect the overall conclusion (not shown).The ratio to depict CD200R function was calculated as: target $^{\text {anti-CD200R/target }}{ }^{\text {isotype }}$ expression so that a value below 1 represents inhibition, and a value above 1 potentiation.

The inhibitory capacity of CD200R was calculated as follows: (\% inhibition in the condition of interest)/( \% inhibition in CD200R-GFP U937) x 100. A value of 100 indicates that the treatment did not affect CD200R function and a value of 0 indicates complete loss of function.

\section{Statistics}

In all figure legends we have indicated the statistical test used to determine significance, and the $\mathrm{n}$ of experiments, or the data of individual donors is depicted. Statistical analysis was performed in Prism 7.1 (GraphPad software) or in R 5.3.1. All tests in this study are twosided. All boxplots are plotted as median with 25 and 75 percentiles with handles range from minimum to maximum values. Bars are mean \pm SEM.

Significance is depicted as: ns: $\mathrm{p}<.1 ; *$ : $\mathrm{p}<.05 ;{ }^{* *}: \mathrm{p}<0.01 ; * * *: \mathrm{p}<0.001 ; * * * *$ : $\mathrm{p}<0.0001$ 
bioRxiv preprint doi: https://doi.org/10.1101/2020.02.06.933739; this version posted February 14,2020 . The copyright holder for this preprint (which was not certified by peer review) is the author/funder, who has granted bioRxiv a license to display the preprint in perpetuity. It is made available under aCC-BY 4.0 International license. 


\section{References}

Affandi, A.J., S.C. Silva-Cardoso, S. Garcia, E.F.A. Leijten, T.S. van Kempen, W. Marut, J.A.G. van Roon, and T. Radstake. 2018. CXCL4 is a novel inducer of human Th17 cells and correlates with IL-17 and IL-22 in psoriatic arthritis. Eur J Immunol 48:522531.

Aref, S., E. Azmy, K. El-Bakry, L. Ibrahim, and M. Mabed. 2018. Prognostic impact of CD200 and CD56 expression in adult acute lymphoblastic leukemia patients. Hematology 23:263-270.

Bennett, L., A.K. Palucka, E. Arce, V. Cantrell, J. Borvak, J. Banchereau, and V. Pascual. 2003. Interferon and granulopoiesis signatures in systemic lupus erythematosus blood. J. Exp. Med 197:711-723.

Borriello, F., J. Lederer, S. Scott, and A.H. Sharpe. 1997. MRC OX-2 defines a novel T cell costimulatory pathway. J Immunol 158:4548-4554.

Chan, S.H., B. Perussia, J.W. Gupta, M. Kobayashi, M. Pospisil, H.A. Young, S.F. Wolf, D. Young, S.C. Clark, and G. Trinchieri. 1991. Induction of interferon gamma production by natural killer cell stimulatory factor: characterization of the responder cells and synergy with other inducers. J Exp Med 173:869-879.

Chen, J.X., L.P. Mei, B.G. Chen, D.L. Wang, W.D. Luo, L.F. Luo, R. Lu, R. Zheng, and L. Zhang. 2017. Over-expression of CD200 predicts poor prognosis in MDS. Leuk Res 56:1-6.

Cox, F.F., D. Carney, A.M. Miller, and M.A. Lynch. 2012. CD200 fusion protein decreases microglial activation in the hippocampus of aged rats. Brain Behav Immun 26:789796.

Crow, M.K., and L. Rönnblom. 2018. Correction: Report of the inaugural Interferon Research Summit: interferon in inflammatory diseases. Lupus Sci Med 5:e000276corr000271.

Dull, T., R. Zufferey, M. Kelly, R.J. Mandel, M. Nguyen, D. Trono, and L. Naldini. 1998. A third-generation lentivirus vector with a conditional packaging system. $J$ Virol 72:8463-8471.

El Din Fouad, N.B., N.Y. Ibrahim, R.S. Abdel Aziz, and S.K. Ibrahim. 2018. CD200 Expression in Diagnostic and Prognostic Assessment of Mature B Cell Lymphophoproliferative Neoplasms. Asian Pac J Cancer Prev 19:3383-3392.

Erin, N., A. Podnos, G. Tanriover, O. Duymus, E. Cote, I. Khatri, and R.M. Gorczynski. 2015. Bidirectional effect of CD200 on breast cancer development and metastasis, with ultimate outcome determined by tumor aggressiveness and a cancer-induced inflammatory response. Oncogene 34:3860-3870. 
bioRxiv preprint doi: https://doi.org/10.1101/2020.02.06.933739; this version posted February 14, 2020. The copyright holder for this preprint (which was not certified by peer review) is the author/funder, who has granted bioRxiv a license to display the preprint in perpetuity. It is made available under aCC-BY 4.0 International license.

Erin, N., G. Tanriover, A. Curry, M. Akman, O. Duymus, and R. Gorczynski. 2018. CD200fc enhances anti-tumoral immune response and inhibits visceral metastasis of breast carcinoma. Oncotarget 9:19147-19158.

Fernandez, D., E. Bonilla, N. Mirza, B. Niland, and A. Perl. 2006. Rapamycin reduces disease activity and normalizes $\mathrm{T}$ cell activation-induced calcium fluxing in patients with systemic lupus erythematosus. Arthritis Rheum 54:2983-2988.

Fukao, T., M. Tanabe, Y. Terauchi, T. Ota, S. Matsuda, T. Asano, T. Kadowaki, T. Takeuchi, and S. Koyasu. 2002. PI3K-mediated negative feedback regulation of IL-12 production in DCs. Nat Immunol 3:875-881.

Geijtenbeek, T.B., S.J. Van Vliet, E.A. Koppel, M. Sanchez-Hernandez, C.M. Vandenbroucke-Grauls, B. Appelmelk, and Y. Van Kooyk. 2003. Mycobacteria target DC-SIGN to suppress dendritic cell function. J Exp Med 197:7-17.

Gringhuis, S.I., J. den Dunnen, M. Litjens, M. van der Vlist, and T.B. Geijtenbeek. 2009. Carbohydrate-specific signaling through the DC-SIGN signalosome tailors immunity to Mycobacterium tuberculosis, HIV-1 and Helicobacter pylori. Nat Immunol 10:1081-1088.

Hoek, R.M., S.R. Ruuls, C.A. Murphy, G.J. Wright, R. Goddard, S.M. Zurawski, B. Blom, M.E. Homola, W.J. Streit, M.H. Brown, A.N. Barclay, and J.D. Sedgwick. 2000. Down-regulation of the macrophage lineage through interaction with OX2 (CD200). Science 290:1768-1771.

Huang, R., Q. Lan, L. Chen, H. Zhong, L. Cui, L. Jiang, H. Huang, L. Li, S. Zeng, M. Li, X. Zhao, and F. Xu. 2018. CD200Fc Attenuates Retinal Glial Responses and RGCs Apoptosis After Optic Nerve Crush by Modulating CD200/CD200R1 Interaction. $J$ Mol Neurosci 64:200-210.

Karnam, G., T.P. Rygiel, M. Raaben, G.C. Grinwis, F.E. Coenjaerts, M.E. Ressing, P.J. Rottier, C.A. de Haan, and L. Meyaard. 2012. CD200 receptor controls sex-specific TLR7 responses to viral infection. PLoS. Pathog 8:e1002710.

Khalil, H., N. Rosenblatt, L. Liaudet, and C. Widmann. 2012. The role of endogenous and exogenous RasGAP-derived fragment $\mathrm{N}$ in protecting cardiomyocytes from peroxynitrite-induced apoptosis. Free Radic Biol Med 53:926-935.

Kretz-Rommel, A., and K.S. Bowdish. 2008. Rationale for anti-CD200 immunotherapy in BCLL and other hematologic malignancies: new concepts in blocking immune suppression. Expert. Opin. Biol. Ther 8:5-15.

Kretz-Rommel, A., F. Qin, N. Dakappagari, E.P. Ravey, J. McWhirter, D. Oltean, S. Frederickson, T. Maruyama, M.A. Wild, M.J. Nolan, D. Wu, J. Springhorn, and K.S. Bowdish. 2007. CD200 Expression on Tumor Cells Suppresses Antitumor Immunity: 
bioRxiv preprint doi: https://doi.org/10.1101/2020.02.06.933739; this version posted February 14, 2020. The copyright holder for this preprint (which was not certified by peer review) is the author/funder, who has granted bioRxiv a license to display the preprint in perpetuity. It is made available under aCC-BY 4.0 International license.

New Approaches to Cancer Immunotherapy. The Journal of Immunology 178:55955605.

Krishnan, S., J.G. Kiang, C.U. Fisher, M.P. Nambiar, H.T. Nguyen, V.C. Kyttaris, B. Chowdhury, V. Rus, and G.C. Tsokos. 2005. Increased caspase-3 expression and activity contribute to reduced CD3zeta expression in systemic lupus erythematosus $\mathrm{T}$ cells. J Immunol 175:3417-3423.

Lai, Z.W., R. Kelly, T. Winans, I. Marchena, A. Shadakshari, J. Yu, M. Dawood, R. Garcia, H. Tily, L. Francis, S.V. Faraone, P.E. Phillips, and A. Perl. 2018. Sirolimus in patients with clinically active systemic lupus erythematosus resistant to, or intolerant of, conventional medications: a single-arm, open-label, phase 1/2 trial. Lancet 391:1186-1196.

Li, L., Y. Tian, C. Shi, H. Zhang, and Z. Zhou. 2016. Over-Expression of CD200 Predicts Poor Prognosis in Cutaneous Squamous Cell Carcinoma. Med Sci Monit 22:10791084.

Li, Y., L.D. Zhao, L.S. Tong, S.N. Qian, Y. Ren, L. Zhang, X. Ding, Y. Chen, Y.X. Wang, W. Zhang, X.F. Zeng, F.C. Zhang, F.L. Tang, X. Zhang, D.N. Ba, W. He, X.T. Cao, and P.E. Lipsky. 2012. Aberrant CD200/CD200R1 expression and function in systemic lupus erythematosus contributes to abnormal $\mathrm{T}$ cell responsiveness and dendritic cell activity. Arthritis Res. Ther 14:R123.

Liu, J.Q., F. Talebian, L. Wu, Z. Liu, M.S. Li, L. Wu, J. Zhu, J. Markowitz, W.E. Carson, 3rd, S. Basu, and X.F. Bai. 2016. A Critical Role for CD200R Signaling in Limiting the Growth and Metastasis of CD200+ Melanoma. J Immunol 197:1489-1497.

Mahadevan, D., M.C. Lanasa, C. Farber, M. Pandey, M. Whelden, S.J. Faas, T. Ulery, A. Kukreja, L. Li, C.L. Bedrosian, X. Zhang, and L.T. Heffner. 2019. Phase I study of samalizumab in chronic lymphocytic leukemia and multiple myeloma: blockade of the immune checkpoint CD200. J Immunother Cancer 7:227.

McWhirter, J.R., A. Kretz-Rommel, A. Saven, T. Maruyama, K.N. Potter, C.I. Mockridge, E.P. Ravey, F. Qin, and K.S. Bowdish. 2006. Antibodies selected from combinatorial libraries block a tumor antigen that plays a key role in immunomodulation. Proc. Natl. Acad. Sci. U. S. A 103:1041-1046.

Mihrshahi, R., A.N. Barclay, and M.H. Brown. 2009. Essential roles for Dok2 and RasGAP in CD200 receptor-mediated regulation of human myeloid cells. J. Immunol 183:4879-4886.

Moon, J.S., S. Hisata, M.A. Park, G.M. DeNicola, S.W. Ryter, K. Nakahira, and A.M.K. Choi. 2015. mTORC1-Induced HK1-Dependent Glycolysis Regulates NLRP3 Inflammasome Activation. Cell Rep 12:102-115. 
bioRxiv preprint doi: https://doi.org/10.1101/2020.02.06.933739; this version posted February 14,2020 . The copyright holder for this preprint (which was not certified by peer review) is the author/funder, who has granted bioRxiv a license to display the preprint in perpetuity. It is made available under aCC-BY 4.0 International license.

Morand, E.F., R. Furie, Y. Tanaka, I.N. Bruce, A.D. Askanase, C. Richez, S.C. Bae, P.Z. Brohawn, L. Pineda, A. Berglind, R. Tummala, and T.-T. Investigators. 2020. Trial of Anifrolumab in Active Systemic Lupus Erythematosus. The New England journal of medicine 382:211-221.

Moreaux, J., D. Hose, T. Reme, E. Jourdan, M. Hundemer, E. Legouffe, P. Moine, P. Bourin, M. Moos, J. Corre, T. Mohler, J. De Vos, J.F. Rossi, H. Goldschmidt, and B. Klein. 2006. CD200 is a new prognostic factor in multiple myeloma. Blood 108:4194-4197.

Okamura, H., H. Tsutsi, T. Komatsu, M. Yutsudo, A. Hakura, T. Tanimoto, K. Torigoe, T. Okura, Y. Nukada, K. Hattori, and et al. 1995. Cloning of a new cytokine that induces IFN-gamma production by T cells. Nature 378:88-91.

Petermann, K.B., G.I. Rozenberg, D. Zedek, P. Groben, K. McKinnon, C. Buehler, W.Y. Kim, J.M. Shields, S. Penland, J.E. Bear, N.E. Thomas, J.S. Serody, and N.E. Sharpless. 2007. CD200 is induced by ERK and is a potential therapeutic target in melanoma. J. Clin. Invest 117:3922-3929.

Popson, S.A., M.E. Ziegler, X. Chen, M.T. Holderfield, C.I. Shaaban, A.H. Fong, K.M. Welch-Reardon, J. Papkoff, and C.C. Hughes. 2014. Interferon-induced transmembrane protein 1 regulates endothelial lumen formation during angiogenesis. Arterioscler Thromb Vasc Biol 34:1011-1019.

Ravetch, J.V., and L.L. Lanier. 2000. Immune inhibitory receptors. Science 290:84-89.

Rosenblum, M.D., E. Olasz, J.E. Woodliff, B.D. Johnson, M.C. Konkol, K.A. Gerber, R.J. Orentas, G. Sandford, and R.L. Truitt. 2004. CD200 is a novel p53-target gene involved in apoptosis-associated immune tolerance. Blood 103:2691-2698.

Ruhland, A., and P.E. Kima. 2009. Activation of PI3K/Akt signaling has a dominant negative effect on IL-12 production by macrophages infected with Leishmania amazonensis promastigotes. Exp Parasitol 122:28-36.

Rygiel, T.P., G. Karnam, G. Goverse, A.P. van der Marel, M.J. Greuter, R.A. van Schaarenburg, W.F. Visser, A.B. Brenkman, R. Molenaar, R.M. Hoek, R.E. Mebius, and L. Meyaard. 2012. CD200-CD200R signaling suppresses anti-tumor responses independently of CD200 expression on the tumor. Oncogene 31:2979-2988.

Rygiel, T.P., A.E. Mertens, K. Strumane, K.R. van der, and J.G. Collard. 2008. The Rac activator Tiam1 prevents keratinocyte apoptosis by controlling ROS-mediated ERK phosphorylation. J. Cell Sci 121:1183-1192.

Rygiel, T.P., E.S. Rijkers, T. De Ruiter, E.H. Stolte, M. van der Valk, G.F. Rimmelzwaan, L. Boon, A.M. van Loon, F.E. Coenjaerts, R.M. Hoek, K. Tesselaar, and L. Meyaard. 2009. Lack of CD200 enhances pathological T cell responses during influenza infection. J. Immunol 183:1990-1996. 
bioRxiv preprint doi: https://doi.org/10.1101/2020.02.06.933739; this version posted February 14, 2020. The copyright holder for this preprint (which was not certified by peer review) is the author/funder, who has granted bioRxiv a license to display the preprint in perpetuity. It is made available under aCC-BY 4.0 International license.

Simelyte, E., G. Criado, D. Essex, R.A. Uger, M. Feldmann, and R.O. Williams. 2008. CD200-Fc, a novel antiarthritic biologic agent that targets proinflammatory cytokine expression in the joints of mice with collagen-induced arthritis. Arthritis Rheum 58:1038-1043.

Snelgrove, R.J., J. Goulding, A.M. Didierlaurent, D. Lyonga, S. Vekaria, L. Edwards, E. Gwyer, J.D. Sedgwick, A.N. Barclay, and T. Hussell. 2008. A critical function for CD200 in lung immune homeostasis and the severity of influenza infection. Nat. Immunol 9:1074-1083.

Soberman, R.J., C.R. MacKay, C.A. Vaine, G.B. Ryan, A.M. Cerny, M.R. Thompson, B. Nikolic, V. Primo, P. Christmas, P. Sheiffele, L. Aronov, D.M. Knipe, and E.A. KurtJones. 2012. CD200R1 supports HSV-1 viral replication and licenses proinflammatory signaling functions of TLR2. PLoS. One 7:e47740.

Souyris, M., C. Cenac, P. Azar, D. Daviaud, A. Canivet, S. Grunenwald, C. Pienkowski, J. Chaumeil, J.E. Mejia, and J.C. Guery. 2018. TLR7 escapes X chromosome inactivation in immune cells. Sci Immunol 3:

Sugai, A., H. Sato, I. Takayama, M. Yoneda, and C. Kai. 2017. Nipah and Hendra Virus Nucleoproteins Inhibit Nuclear Accumulation of Signal Transducer and Activator of Transcription 1 (STAT1) and STAT2 by Interfering with Their Complex Formation. $J$ Virol 91:

van de Weijer, M.L., M.C. Bassik, R.D. Luteijn, C.M. Voorburg, M.A. Lohuis, E. Kremmer, R.C. Hoeben, E.M. LeProust, S. Chen, H. Hoelen, M.E. Ressing, W. Patena, J.S. Weissman, M.T. McManus, E.J. Wiertz, and R.J. Lebbink. 2014. A high-coverage shRNA screen identifies TMEM129 as an E3 ligase involved in ER-associated protein degradation. Nat Commun 5:3832.

Wang, J., J. Sun, L.N. Liu, D.B. Flies, X. Nie, M. Toki, J. Zhang, C. Song, M. Zarr, X. Zhou, X. Han, K.A. Archer, T. O'Neill, R.S. Herbst, A.N. Boto, M.F. Sanmamed, S. Langermann, D.L. Rimm, and L. Chen. 2019. Siglec-15 as an immune suppressor and potential target for normalization cancer immunotherapy. Nat Med 25:656-666.

Wright, G.J., M. Jones, M.J. Puklavec, M.H. Brown, and A.N. Barclay. 2001. The unusual distribution of the neuronal/lymphoid cell surface CD200 (OX2) glycoprotein is conserved in humans. Immunology 102:173-179.

Wright, G.J., M.J. Puklavec, A.C. Willis, R.M. Hoek, J.D. Sedgwick, M.H. Brown, and A.N. Barclay. 2000. Lymphoid/neuronal cell surface OX2 glycoprotein recognizes a novel receptor on macrophages implicated in the control of their function. Immunity 13:233242.

Wu, N., and A. Veillette. 2016. SLAM family receptors in normal immunity and immune pathologies. Curr Opin Immunol 38:45-51. 
bioRxiv preprint doi: https://doi org/10.1101/2020.02 06 933739: this version posted February 14,2020 . The copyright holder for this

Yang, J.Y., D. Michod, J. Walicki, B.M. Murphy, S. Kasibhatla, S.J. Martin, and C.

Widmann. 2004. Partial cleavage of RasGAP by caspases is required for cell survival in mild stress conditions. Mol Cell Biol 24:10425-10436.

Yin, Y., L. Zhao, F. Zhang, and X. Zhang. 2016. Impact of CD200-Fc on dendritic cells in lupus-prone NZB/WF1 mice. Sci Rep 6:31874.

Zhang, S., H. Cherwinski, J.D. Sedgwick, and J.H. Phillips. 2004. Molecular mechanisms of CD200 inhibition of mast cell activation. Journal of Immunology 173:6786-6793. 
Figures and figure legends.

Vlist et al. Figure 1

A

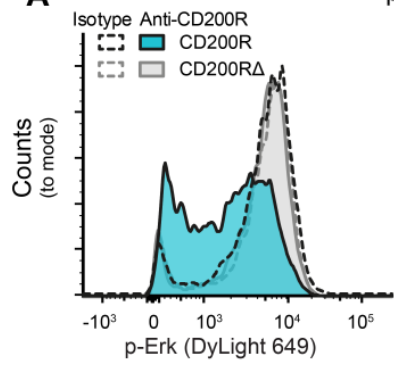

C

Isotype Anti-CD200R

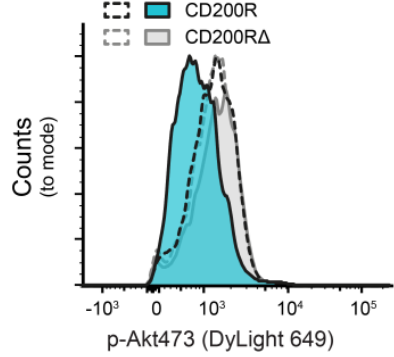

p-Akt473

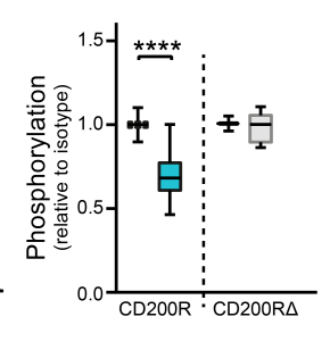

E p-Erk $\quad$ F

F IL-8
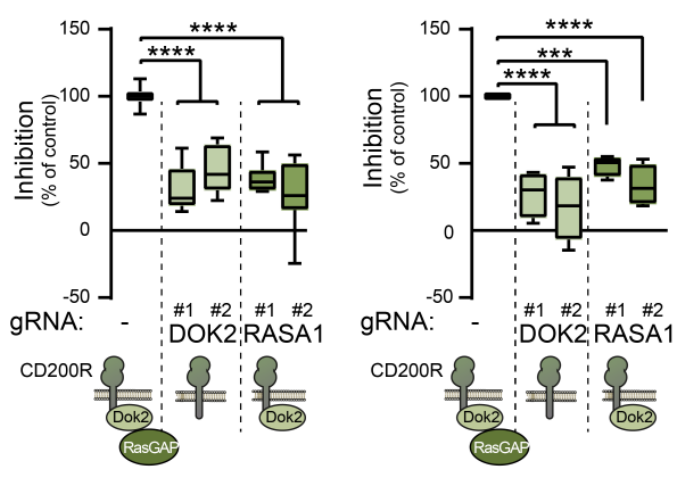

I

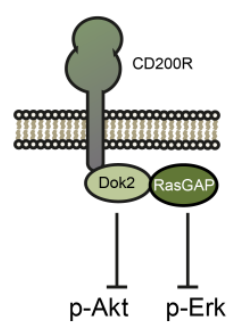

B

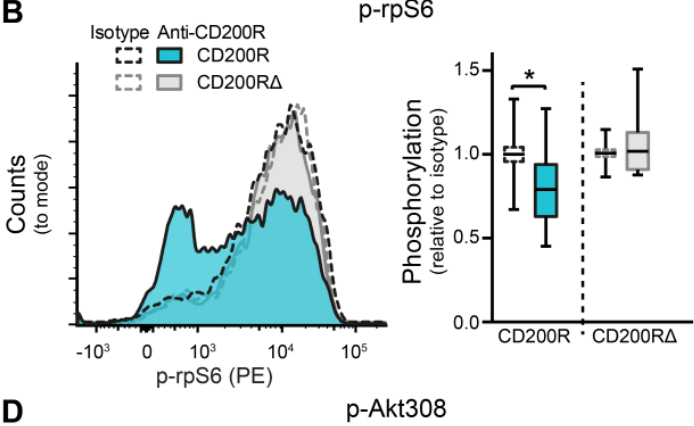

D
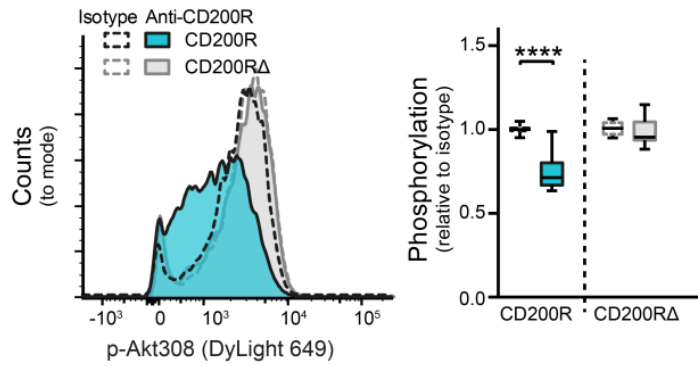

G

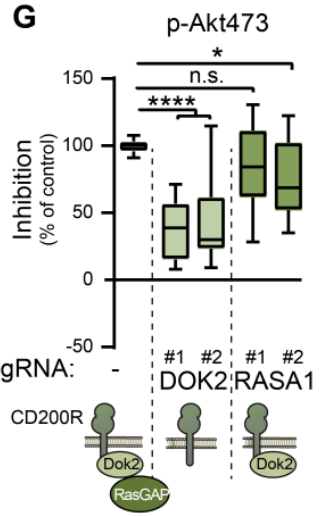

H

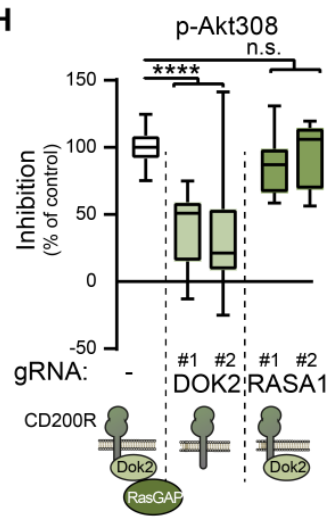

Figure 1. CD200R signaling bifurcates at the level of Dok2. 
(A-D) Phosphorylation of pErk ( $\mathrm{n}=16$, from 8 experiments), p-Akt473 (n=14, from 7 experiments), p-Akt308 (n=14, from 7 experiments) and p-rpS6 (n=7, from 7 experiments) in U937-CD200R-GFP (Blue) or CD200RA-GFP (Gray) cells after 1h stimulation with antiCD200R (filled histogram) or isotype control (open histogram) as determined by intracellular flow cytometry. Significance was determined by a t test with Welch correction. The data are normalized to isotype stimulated cells within experiments. See supplemental figure $1 \mathrm{~A}$ for expression of CD200R and CD200R $\Delta$ and gating strategy.

(E-H) The effect of removal of Dok2 or RasGAP, using two different guide RNA per target, on the inhibitory capacity of CD200R-GFP on (E) p-Erk (n=8, from 4 experiments), (F) IL-8 secretion ( $\mathrm{n}=4$, from 4 experiments), (G) p-Akt473 (n=13, from 7 experiments) and (H) pAkt308 ( $\mathrm{n}=13$, from 7 experiments). CD200R was ligated with an agonistic antibody or isotype control on U937-CD200R-GFP polyclonal lines deficient for Dok2 or RasGAP. Within experiments, data were normalized to the parental cell line and tested for significance by one-way ANOVA with Holm-Sidak's correction. Data are obtained in at least 4 independent experiments. Boxplots: median with 25 and 75 percentiles and bars represent minimum and maximum values.

(I) A model of CD200R signaling. CD200R-signaling bifurcates at the level of Dok2. Dok2 is required for inhibition of Akt and recruitment of RasGAP. Subsequently, RasGAP inhibits Ras/Erk signaling. 
Vlist et al. Figure 2
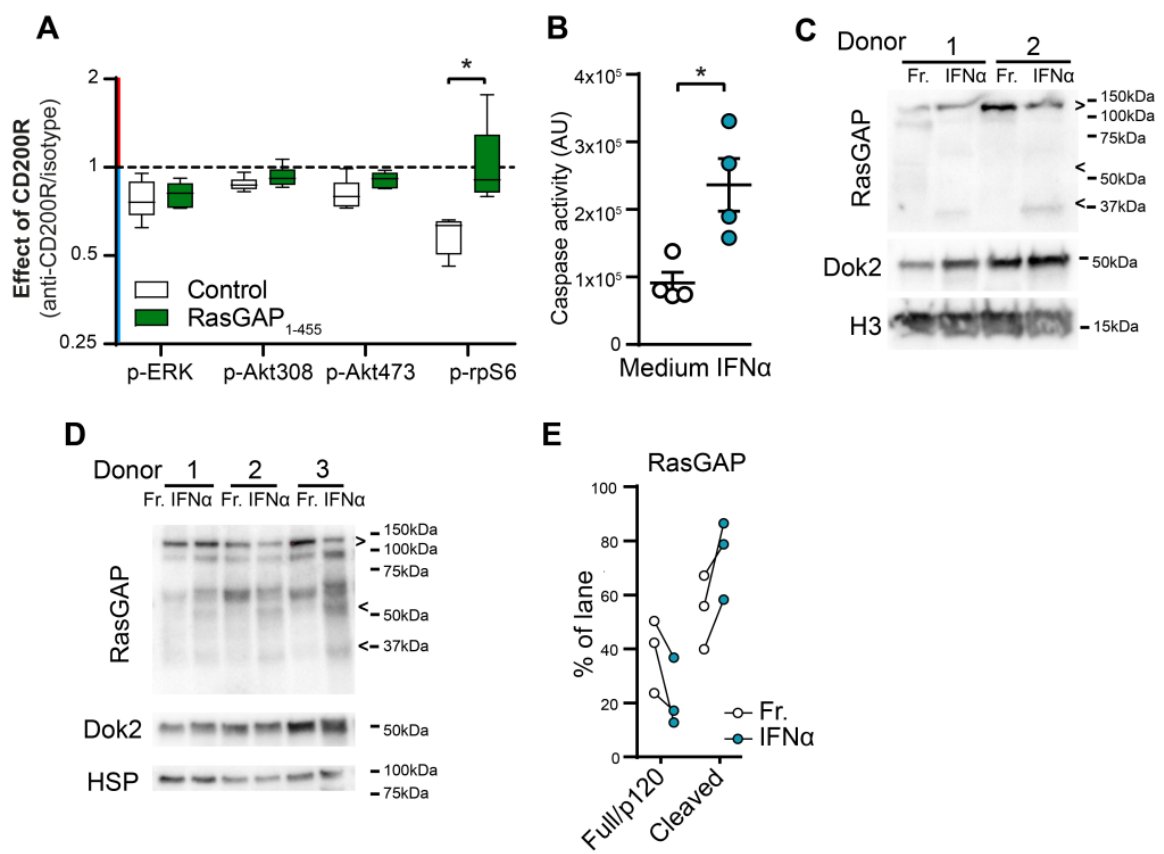

Figure 2. Cleaved RasGAP alters CD200R-signaling

(A) Phosphorylation of p-Akt308, p-Akt473, p-Erk, and p-S6 after 1h stimulation of CD200R with agonistic-antibodies or isotype control in CD200R-U937-cells that over-express fulllength RasGAP/p120 or RasGAP 1 -455. Data were normalized to isotype-stimulated cells. Significance was determined by a t test with Welch correction $(n=6)$.

(B) Caspase activity in fresh and IFN $\alpha$ stimulated PBMC as measured by CaspGlo 3/7 assay. Significance was determined by a t test $(n=4)$.

$(\mathbf{C}, \mathbf{D})$ Western blot analysis of RasGAP and Dok-2 protein expression and cleavage in fresh (Fr.) or 16h IFNa stimulated cells. Blots are lysates of (C) CD14 $4^{+}$monocytes and (D) PBMC cultures. >: full length RasGAP/p120; <: published RasGAP cleavage fragment (Yang et al., 2004). H3: Histone 3. HSP: heat shock protein 90.

(E) Quantification of Figure 2D. Data represent the amount full length RasGAP/p120 or the amount of cleaved RasGAP as percentage of signal in the whole lane. Significance was determined by paired-t test. 
Vlist et al. Figure 3
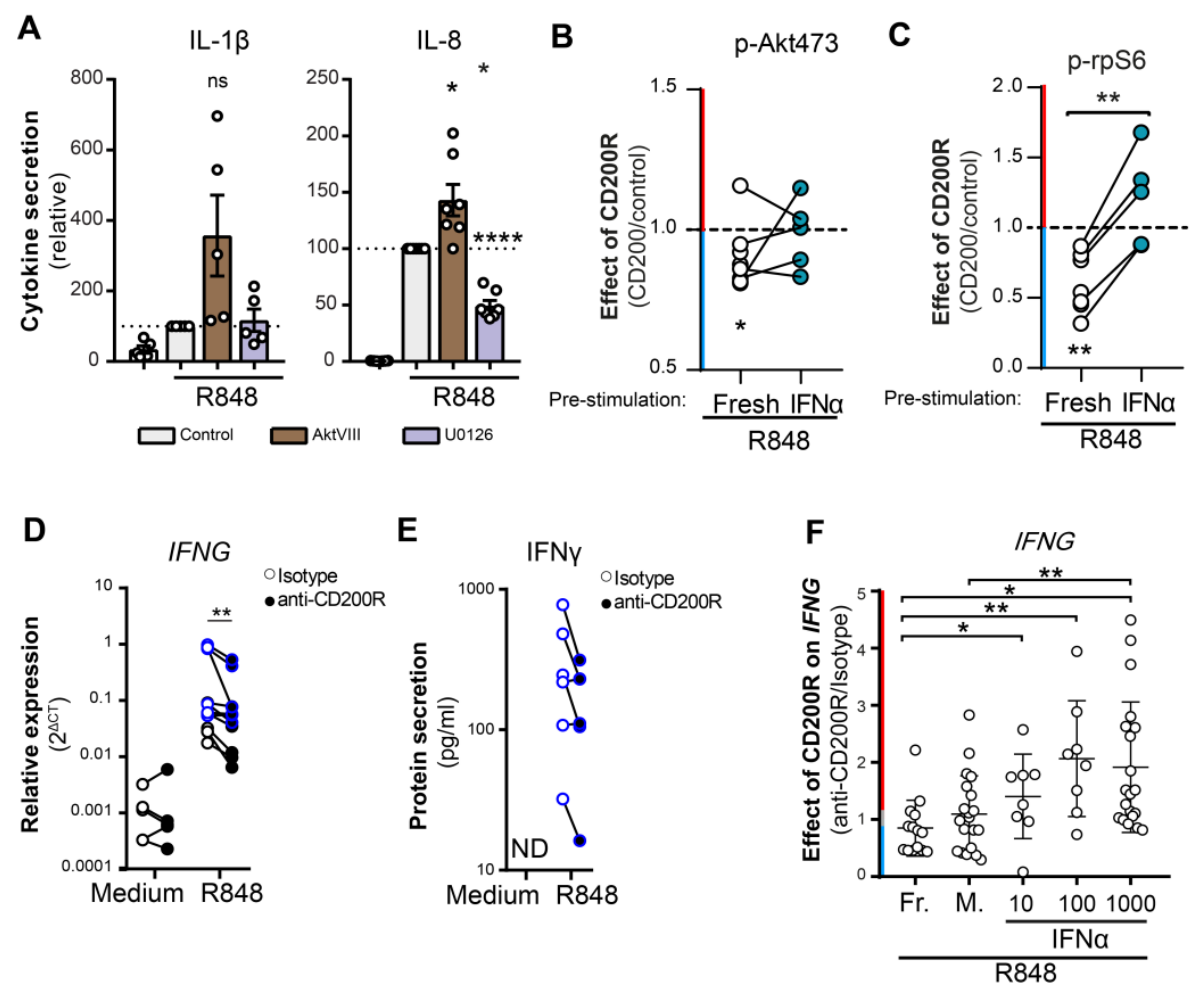

Figure 3. Exposure to type I IFN reverses CD200R function in PBMC

(A) Cytokine secretion by moDC stimulated with R848 for $6 \mathrm{~h}$ in presence of control, Aktinhibitor AktVIII or Mek-inhibitor U0126. IL-1ß: n=5, IL-8: n=8. Significance was determined by one-sample t test.

(B, C) Phosphorylation of p-Akt473 and p-rpS6 in HC moDC. Fresh replated (n=8, 3 samples without IFN-counterpart) or IFN $\alpha$-stimulated (16h, $n=5$, paired with fresh samples) moDCs were seeded on plates coated with control (recombinant human CD200R1, rhCD200R1) or recombinant human CD200 (rhCD200). After 2h pre-incubation, the moDC were stimulated with $1 \mu \mathrm{g} / \mathrm{ml}$ R848 for 30 minutes. Phosphorylation was assessed by flow cytometry. Depicted is the ratio of phosphorylation in CD200-stimulated conditions over control stimulated conditions. Significance between the effect of CD200R on fresh and IFN $\alpha$ stimulated cells was determined by t test. Significance of the effect of CD200R in medium or 
IFN $\alpha$ stimulated cells was determined by one-sample t test.

(D, E) mRNA ( $\mathrm{n}=11)$ and protein $(\mathrm{n}=6)$ data on R848-induced IFNG or IFN $\gamma$ production in PBMC. Donors with blue lines are matched between mRNA and protein data. Significance was determined by Wilcoxon test. ND = not detectable.

(F) The ratio of R848 induced IFNG mRNA production of PBMC stimulated with antiCD200R over PBMC stimulated with isotype. IFNG mRNA production was measured in healthy control PBMC that were used fresh after isolation (Fr., $n=14)$, or have been cultured for $16 \mathrm{~h}$ in medium (Med, $n=20), 10(n=8), 100(n=8)$ or $1000(n=20) U / m l$ of IFN $\alpha$ prior to ligation of CD200R with an agonistic antibody and stimulation of TLR7/8 with R848 for 4h. Significance was determined by a paired t test with Welch correction. 
Vlist et al. Figure 4
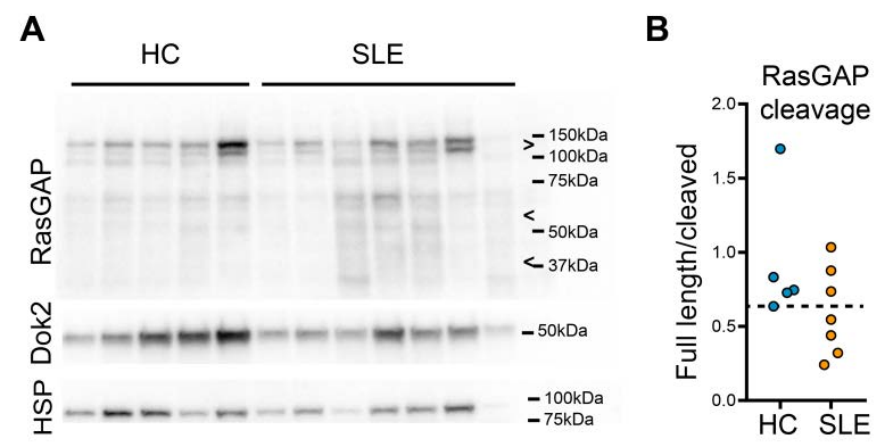

Figure 4. Cleaved RasGAP in systemic lupus erythematosus patients

(A) Western blot analysis of RasGAP and Dok-2 protein expression in healthy control (HC) or systemic lupus erythematosus (SLE) patients’ PBMC. >: Full length RasGAP/p120, <: known caspase 3 cleavage fragments (Yang et al., 2004). HSP: heat shock protein 90 loading control.

(B) Quantification of Figure 4A. Data represent the ratio of full length RasGAP/p120 or the amount of cleaved RasGAP as percentage of signal in the whole lane. Significance was determined by Wilcoxon test, p=.2677. 
Vlist et al. Figure 5

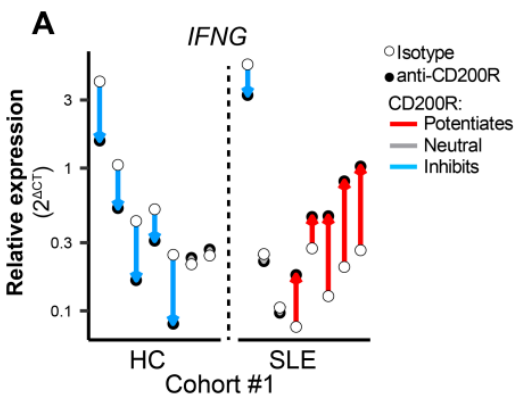

B

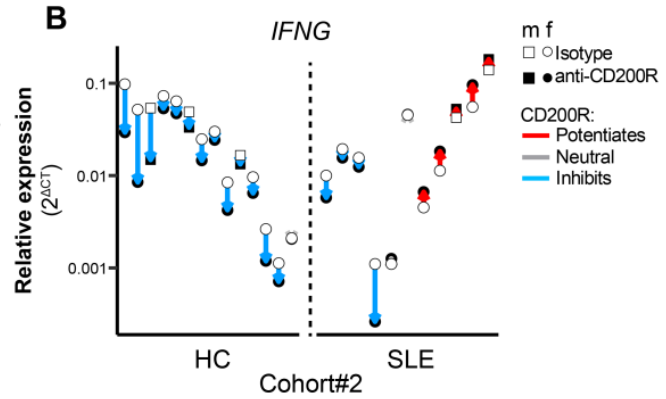

C

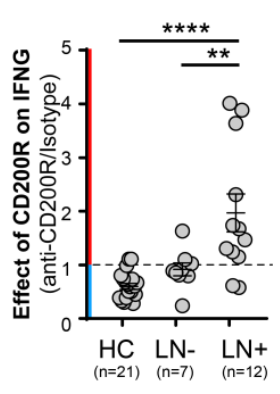

Figure 5. CD200R potentiates IFNG mRNA production in systemic lupus erythematosus patients.

(A, B) IFNG mRNA production relative to GAPDH (A) or B2M (B) by healthy control and SLE patients' PBMC in two cohorts. PBMC were seeded on an isotype control (open circles) or an agonistic anti-CD200R antibody (filled circles) prior to stimulation with R848 for 4h. Each connected dot represents one patient/control. The color of the connecting arrow indicates: inhibition by CD200R ligation (blue, >15\% inhibition compared to isotype control); potentiation by CD200R ligation (red, >15\% potentiation compared to isotype control); or no effect of CD200R ligation (grey, $<15 \%$ inhibition or $<15 \%$ potentiation compared to isotype control).

(C) Ratio of R848-induced IFNG mRNA production from data in fig. 5A and 5B, grouped to HC, SLE patients without lupus nephritis (LN-) and patients with (a history of) lupus nephritis (LN+). Significance was determined with a one-way ANOVA. 